\title{
Performance Analysis of Microstrip Conformal Antenna Array and Effect of Mutual Coupling for Different Curvature
}

\author{
Prashansha Kumari \\ Department of Electronics\& \\ Communication Engineering \\ DIT University, Dehradun \\ UK, India
}

\author{
Brajlata Chauhan \\ Department of Electronics\& \\ Communication Engineering \\ DIT University, Dehradun \\ UK, India
}

\author{
Sandip Vijay \\ Department of Electronics\& \\ Communication Engineering \\ DIT University, Dehradun \\ UK, India
}

\begin{abstract}
This geometry can offer certain characteristics that can't be achieve by planner antenna. Antenna is design to function in $2.4 \mathrm{GHz}$ wireless radio band. This work present performance of 4-element conformal antenna array for cylindrical surface and observe effect of mutual coupling between patch. In this, angle is preserved to conform the shape to reduce extra drag. The radius of cylinder is considered to be atleast one quarter wavelength or slightly more. The simulated results shows its resonant frequency is not affected with change in curvature however the radiation patterns are significantly affected more in elevation direction and less in azimuth. Simulations has been carried on CST software.
\end{abstract}

\section{Keywords}

Conformal antenna array, CST studio suite, mutual coupling, microstrip patch antenna.

\section{INTRODUCTION}

Conformal antenna used in many application like satellite communication, aircrafts and military airborne surveillance radars that required an antenna to operate on a curved surface [1-8]. Conformal antenna is built so that it can integrated easily with the structure without causing any extra drag. Conformal antenna can be define as an antenna that conforms to prescribed shape. The shape is determined by consideration other than electromagnetic for example aerodynamic or hydrodynamic. The microstrip conformal antenna having advantages like simple structure easy manufacture, low coast, convenient integration makes the antenna less disturbing, less visible to the human eye. However there is also some disadvantages like lower efficiency and narrow bandwidth due to surface waves, feeding loss, dielectric loss. Hence to design antenna for prescribed shape without reducing performance is our new challenge [9-13].

Antenna array is known as conformal array when the elements of antenna are conformed on the surface like cylinder, sphere, a cone or other similar without causing extra drag. Most of the real world can be approximated to the cylindrical shape hence analysis of the cylindrical microstrip patch antenna is preferred here. Antenna having single element generally having relatively low directivity and broad radiation pattern. Some application required high directivity antenna since high directivity can achieved by increasing the size of antenna or increasing the number of element in antenna[14-20].

Conformal shape can be slightly curved, singly curved, doubly curved and cylindrical array. The slightly curved antenna behaves more or less as planner antenna. The design are roughly the same. To make general statement for the other type antenna are difficult because of so different requirement like dimension, shape, element types etc. While designing the element in the antenna array we need to give importance to aspect such as effects of mutual coupling between antennas. Grating lobes created due to the mutual coupling ant it suppressed by the evenly distribution of element over antenna surface or obtaining high element density. Roughly the spacing between the elements is half wavelength[21-24].

\section{CONFORMAL MAPPING}

Conformal mapping technique is very simple and close approximation besides involving simpler function rather than tiresome integrals equations are involved in other techniques. The conformal mapping of a boundary is between the dielectrics which is valid since it hold the angle of refraction of electric field at the boundaries.

Assume a complex function given below for mapping:

$$
f(z)=u(x, y)+i v(x+y)
$$

Which gives mapping of its domain $\mathrm{D}$ in the complex z-plane into the complex w-plane. Consider that

$$
\begin{aligned}
& w=f(z)=z^{2} \\
& u=\operatorname{Re}\left(z^{2}\right)=x^{2}-y^{2} \\
& v=\operatorname{Im}\left(z^{2}\right)=2 x y
\end{aligned}
$$

Here the line $\mathrm{x}=\mathrm{c}$ is constant and $\mathrm{y}=\mathrm{k}=$ is constant and mapped onto the Parabolas opens to the left and right

$$
\begin{aligned}
& v^{2}=4 c^{2}\left(c^{2}-u\right) \\
& v^{2}=4 k^{2}\left(k^{2}-u\right)
\end{aligned}
$$



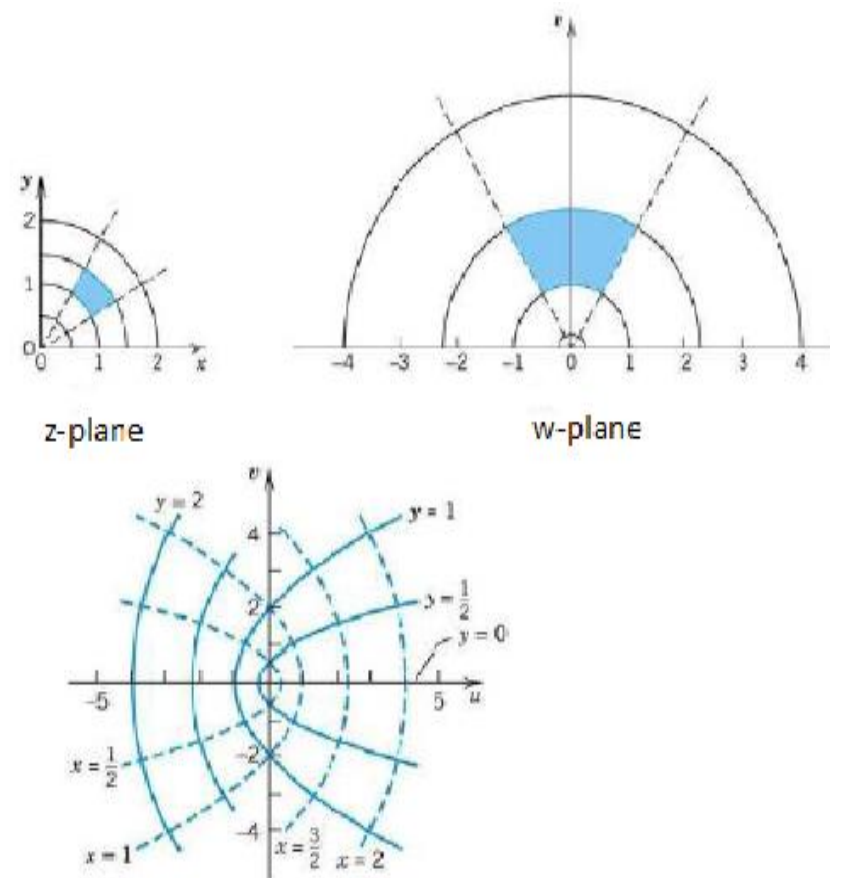

w-plane

Fig.1. Mapping onto a prescribed shape

A mapping of w-plane is function of z-plane except critical point that is at which the derivative $f^{\prime}$ become zero. Consider that, $\mathrm{w}=\mathrm{f}(\mathrm{z})$ and the angle between two intersecting curves is $\alpha$ and angle lies between 0 and $\pi(0 \leq \alpha \leq \pi)$ as shown in fig.

2. Assume that curve $\mathrm{C}$ having

$$
\begin{aligned}
& z(t)=x(t)+i y(t) ; \text { in domain of } \mathrm{f}(\mathrm{z}) \\
& \dot{z}(t)=\frac{d z}{d t}=\dot{x}(t)+i \dot{y}(t) ; \text { is tangent to } C
\end{aligned}
$$

We can say that conformal for $\mathrm{C}$ is, $\mathrm{B}=\mathrm{w}=\mathrm{f}(\mathrm{z}(\mathrm{t}))$

According to chain rule, $\dot{w}(t)=f^{\prime}(z(t)) \dot{z}(t)$

Hence the tangent direction of $\mathrm{B}$ is $\arg \dot{w}=\arg f^{\prime}+\arg \dot{z}$

Where $\arg \dot{z}$ gives direction of $\mathrm{C}$.

From figure 2(a) we can say that the mapping rotates in all direction at appoint $\mathrm{z} 0$ in the domain of analytic of function $\mathrm{f}$ through the some angle argf, which exist till $\mathrm{f}^{\prime \prime}(\mathrm{z} 0) \mathrm{n}$ eq0.

$$
w=z^{n}, n=2.3 \ldots \ldots \text { is conformal except at } z=0
$$

Where $w^{\prime}=n z^{n-1}=0$, generally $\mathrm{n}$ the angle at 0 are multiplied by factor $\mathrm{n}$ while mapping hence $0 \leq \theta \leq \pi / \mathrm{n}$ is mapped by $z^{n}$ onto upper half plane $v \geq 0$.

Conformality is the most important geometric property of analytic functions and give possibility of a geometric approach to complex analysis.
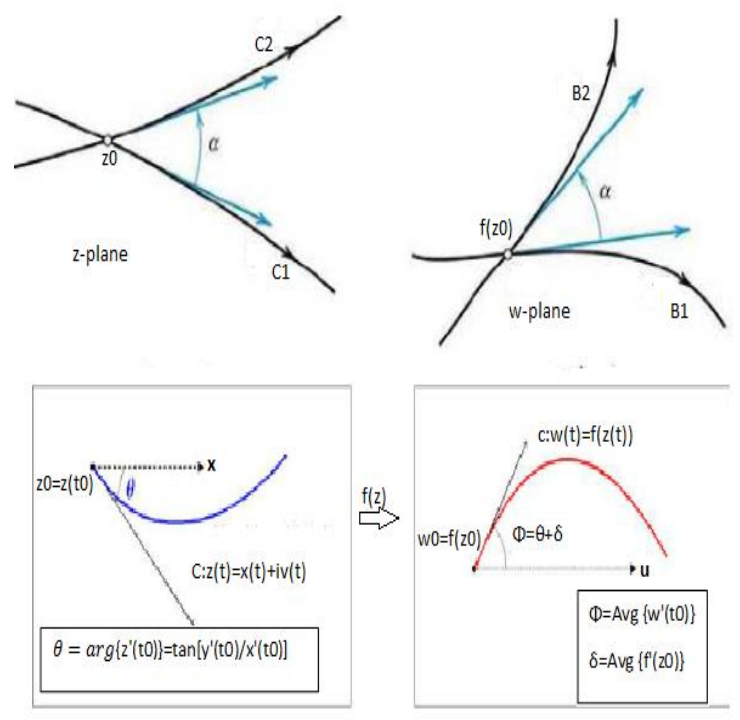

(a)

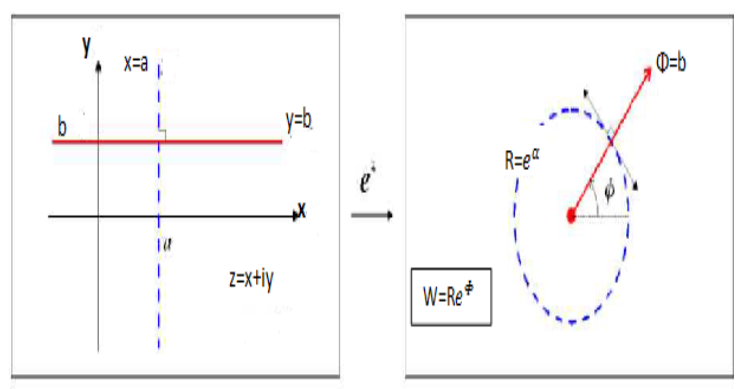

(b)

Fig.2. conformal mapping onto a prescribed shape

\section{FOUR-ELEMENT CONFORMAL ANTENNA ARRAY DESIGN}

The elements of the array consisted of individual microstrip patches which is design to operate at $2.4 \mathrm{GHz}$ frequency. Each patch was printed on a single grounded Rogers 5880 $\mathrm{RT} /$ duroid substrate $(\varepsilon \mathrm{r}=2.2$, $\tan \delta=0.00009)$ [34] with a thickness of $1.575 \mathrm{~mm}$. The radius of cylinder used in simulation is $0.24 \lambda$ and $0.32 \lambda$.

\subsection{Single Element Antenna Structure:}

The design of the planner rectangular patch antenna is shown in Figure 3(a). The dimensions of the entire microstrip patch are given in Table 1. Figure 3(b) shows the return loss response of the patch element antenna. The design procedure are as follows [25-28].

\section{FORMULATIONS:}

A. Calculation of Width

The width of microstrip antenna is given by

$$
w=\frac{C}{2 f o \sqrt{\left(\frac{\varepsilon r+1}{2}\right)}}
$$

B. Calculation of Effective dielectric constant :

$$
\text { creff }=\frac{\varepsilon r+1}{2}+\frac{\varepsilon r-1}{2}\left[1+12 \frac{h}{w}\right]^{\frac{1}{2}}
$$


C. Calculation of Length Extension $(\Delta \mathrm{L})$ :

$$
\Delta L=0.412 \frac{(\text { creff } \pm 0.3)\left(\frac{w}{h}+0.264\right)}{(\varepsilon r e f f-0.258)\left(\frac{w}{h}+0.8\right)}
$$

D. Calculation of Actual Length (L):

The actual length of radiating patch obtained by:

$$
\text { Leff }=L-2 \Delta L \quad \& \quad \text { Leff }=\frac{c}{2 f o \sqrt{\text { rreff }}}
$$

E. Calculation of Ground dimension $(\mathrm{Lg}, \mathrm{Wg})$ :

$$
L g=6 h+L \text { and } W g=6 h+W
$$

Table 1: Antenna dimensions in $\mathbf{m m}$.

\begin{tabular}{|l|l|l|l|}
\hline L & W & L1 & W1 \\
\hline 60 & 88 & 41.08 & 39.03 \\
\hline L2 & W2 & L3 & W3 \\
\hline 0.72 & 24.05 & 4.84 & 15 \\
\hline
\end{tabular}
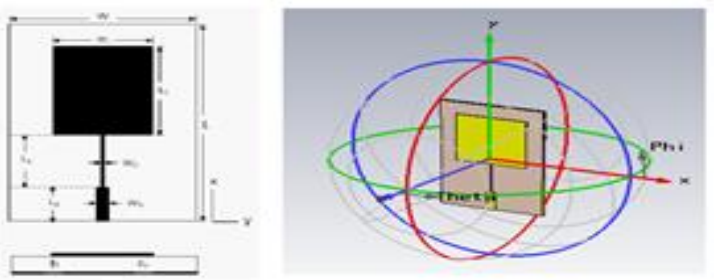

(a)

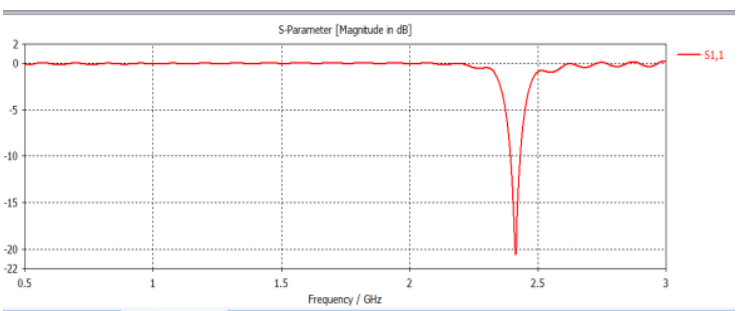

(b)

Figure 3: (a) The layout of single element patch antenna structure, and (b) is its return loss $S 11(\mathrm{~dB})$ response for single element patch antenna

\subsection{The Proposed Conformal Antenna Array Structure}

The elements of the array consisted of individual microstrip patch with spacing of $0.24 \lambda$ and $0.32 \lambda$. Patch elements were equally spaced on cylindrical substrate of $1.57 \mathrm{~mm}$ Rogers $5880 \mathrm{RT} /$ duroid. Conductive material for proposed design is $0.7 \mathrm{~mm}$ thick copper. The height of cylinder is $90 \mathrm{~mm}$ and radius of the cylinder should be atleast one quarter wavelength. The $3 \mathrm{D}$ view of 4 -element conformal antenna is shown in fig. 4 .
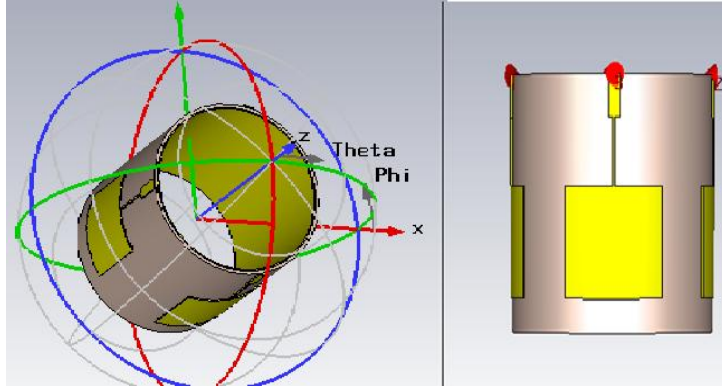

Figure 4: Geometry of proposed antenna.

\section{S-PARAMETER AND RADIATION PATTERN RESULTS OBTAINED BY SIMULATION}

The result shows that the resonant frequency is not affected by curvature however the radiation patterns are significantly affected as shown in fig.5 and fig.6.The radiation pattern in the elevation direction is strongly dependent on the cylinder radius but azimuth angles much less dependent on the cylinder radius.
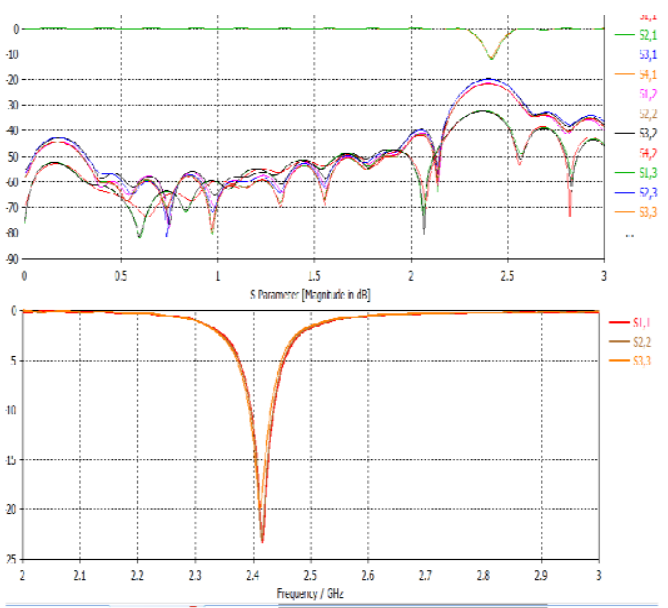

(a)
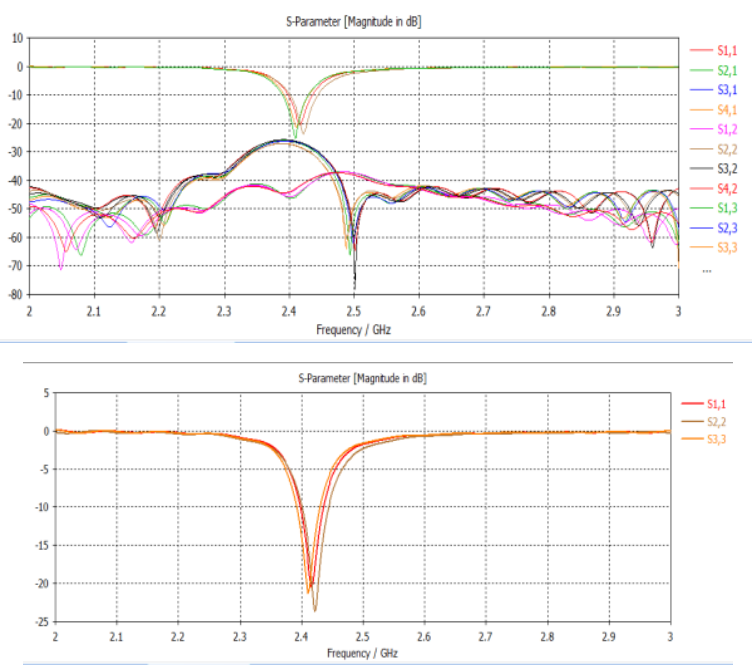

(b)

Figure 5: Simulated coupling of the 4-element array conformed on cylinders with radii of (a) $30 \mathrm{~mm}$ and (b) $40 \mathrm{~mm}$. 

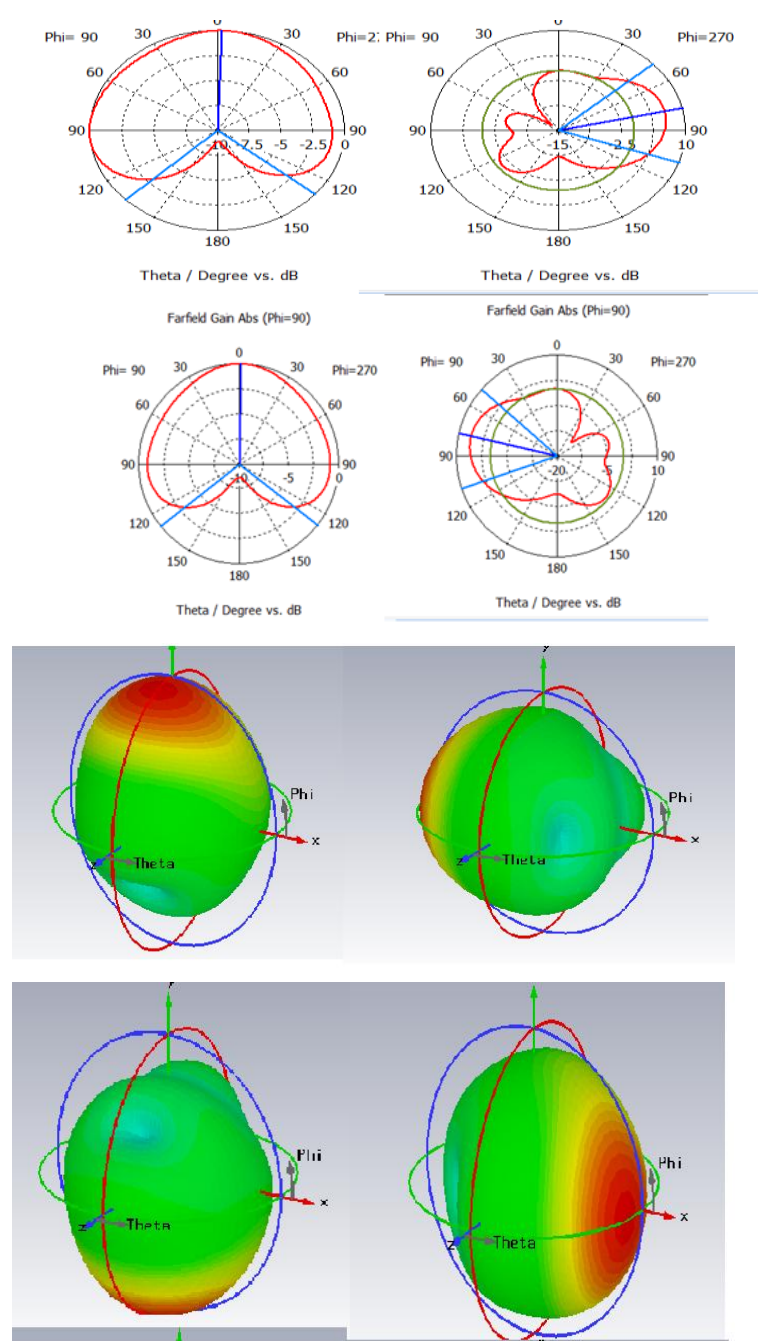

(a)
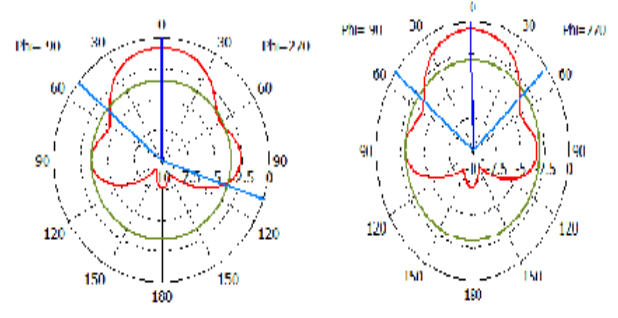

Than / Thegrm va. AR

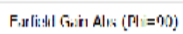

hate? I Dacena ve. dil

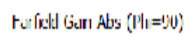
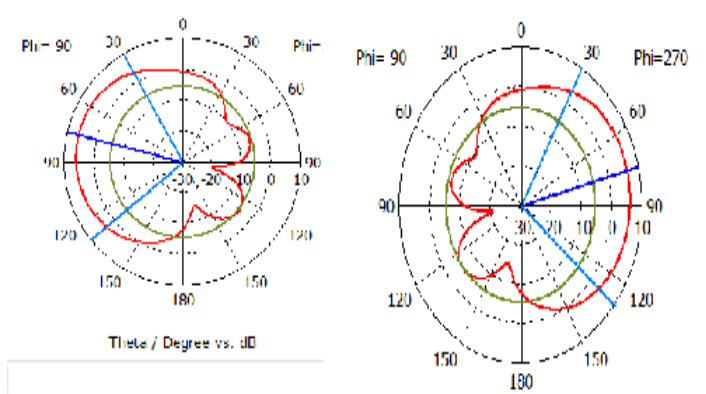

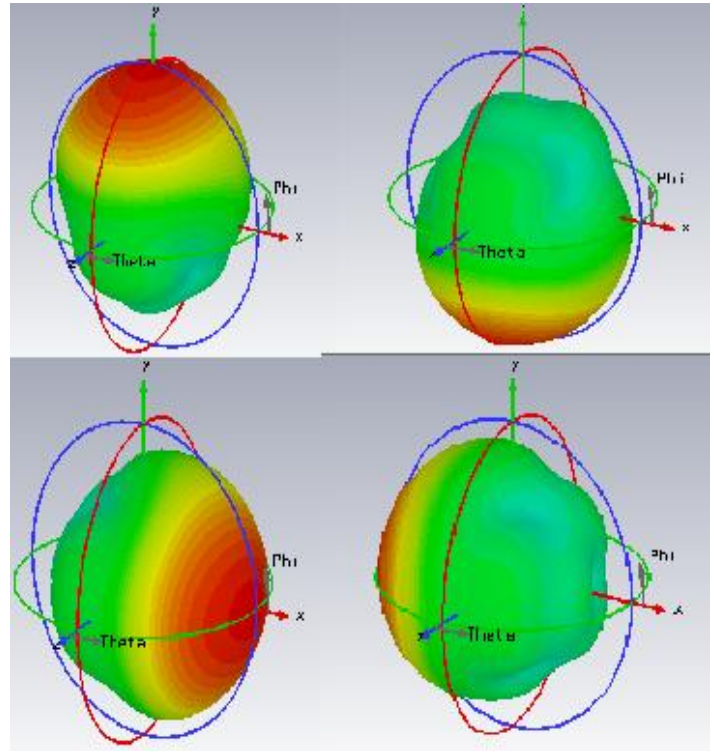

(b)

Figure 5: Radiation patterns: (a) for element in cylindrical array, the radius of cylinder is $R=30 \mathrm{~mm}$ and (b) radius of cylinder is $R=40 \mathrm{~mm}$

Table 2: Gain and Directivity for elements in cylindrical array (a) for the radius of cylinder is $R=30 \mathrm{~mm}$ and (b) radius of cylinder is $R=40 \mathrm{~mm}$

\begin{tabular}{|l|l|l|l|l|}
\hline & Port 1 & Port 2 & Port3 & Port4 \\
\hline Gain & $6.328 \mathrm{db}$ & $6.159 \mathrm{db}$ & $6.128 \mathrm{db}$ & $6.338 \mathrm{db}$ \\
\hline Directivity & $6.722 \mathrm{dbi}$ & $6.541 \mathrm{dbi}$ & $6.493 \mathrm{dbi}$ & $6.724 \mathrm{dbi}$ \\
\hline
\end{tabular}

(a)

\begin{tabular}{|c|c|c|c|c|}
\hline & Port 1 & Port 2 & Port3 & Port4 \\
\hline Gain & $6.45 \mathrm{db}$ & $6.135 \mathrm{db}$ & $6.11 \mathrm{db}$ & $6.03 \mathrm{db}$ \\
\hline Directivity & $6.45 \mathrm{dbi}$ & $6.625 \mathrm{dbi}$ & $6.420 \mathrm{dbi}$ & $6.46 \mathrm{dbi}$ \\
\hline
\end{tabular}

(b)

\section{CONCLUSION}

For the designing of the conformal microstrip antenna on a cylindrical surface it is important to study the effect of mutual coupling. In this paper we study with the inter element space between the element is $0.24 \lambda$ and $0.32 \lambda$. When the cylindrical radius is more than one quarter wavelength then only acceptable mutual can be obtained. The element pattern of antenna get rises due to the mutual coupling in array. This paper also conclude the detailed performance analysis of Sparameter, gain, directivity, radiation pattern in $\theta$ and $\Phi$ plane for 4-element conformal antenna array as shown in table 2 . Resonant frequency of antenna does not affected the radius of cylinder while ration pattern is affected. This type of antenna suitable for radar application and wireless communication system.

\section{REFERENCES}

[1] P. L. O'Donovan and A. W. Rudge, "Adaptive control of a flexible linear array," Electron. Lett, vol. 9, no. 6, pp. 121-122, Mar. 22, 1973.

[2] D. J. Chung, S. K. Bhattacharya, G. E. Ponchak, and J. Papapolymerou, "An $8 \times 8$ lightweight flexible multilayer antenna array," presented at the IEEE 
Antennas Propag. Soc. Int. Symp., Charleston, SC, Jun. $1-5,2009$.

[3] R. C. Hansen, Phased Array Antennas. NewYork: Wiley, 1998.

[4] R. L. Haupt, Antenna Arrays: A Computational Approach. Hoboken, NJ: Wiley, 2010.

[5] S. Nikolaou, G. E. Ponchak, J. Papapolymerou, and M. M. Tentzeris, "Conformal double exponentially tapered slot antenna (DETSA) on LCP or UWB applications," IEEE Trans. Antennas Propag., vol. 54, no. 6, pp. 16631669, Jun. 2006.

[6] J.-L. Guo and J.-Y. Li, "Pattern synthesis of conformal array antenna in the presence of platform using differential evolution algorithm," IEEE Trans. Antennas Propag., vol. 57, no. 9, pp. 2615-2621, Sep. 2009.

[7] M. A. Aziz, S. Roy, L. A. Berge, I. Ullah, and B. D. Braaten, "A conformal CPW folded slot antenna array printed on a Kapton substrate," presented at the Eur. Conf. Antennas Propag. (EuCAP), Prague, Czech Republic, Mar. 2012.

[8] K. Wincza and S. Gruszczynski, "Influence of curvature radius on radiation patterns in multibeam conformal antennas," in Proc. 36th Eur. Microw. Conf., Sep. 10-15, 2006, pp. 1410-1413.

[9] H. Schippers, G. Spalluto, and G. Vos, "Radiation analysis of conformal phased array antennas on distorted structures," in Proc. 12th Int. Conf. Antennas and Propagation, Mar. 31-Apr. 3 2003, pp. 160-163.

[10] H. Schippers, J. Verpoorte, P. Jorna, A. Hulzinga, A. Meijerink, C. Roeloffzen, R. G. Heideman, A. Leinse, and M. Wintels, "Conformal phased array with beam forming on airborne satellite communication," in Proc. Int. ITG Workshop on Smart Antennas, Feb. 26-27, 2008, pp.343-350.

[11] H. Schippers, P. Knott, T. Deloues, P. Lacomme, and M. R. Scherbarth, "Vibrating antennas and compensation techniques research in NATO/ RTO/SET 087/RTG 50," in Proc. IEEE Aerospace Conf., Mar. 3-10, 2007, pp. 113.

[12] P. Jorna, H. Schippers, and J. Verpoorte, "Beam synthesis for conformal array antennas with efficient tapering," presented at the 5th Eur. Workshop on Conformal Antennas, Bristol, U.K., Sep. 11-12, 2007.

[13] P. Knott, "Deformation and vibration of conformal antenna arrays and compensation techniques," in Proc. Meet. RTO-MP-AVT-141, 2006, pp. 1-12, paper 19.

[14] Pawel, K., O. Przemyslaw, and H. Pawel, "TTC patch antennas made in a conformal form with small radius," Proceeding of 'Eu CAP 2006', Nice, France, Nov. 6-10, 2006.

[15] Wang, Q. and Q.-Q. He, “An arbitrary conformal array pattern synthesis method that includes mutual coupling and platform effects," Progress In Electromagnetics Research, Vol. 110, 297-311, 2010.

[16] Josefsson, L. and P. Persson, Conformal Array Antenna Theory and Design, Wiley-Inter Science, 2006.

[17] Niksa, B. and S. Zvonimir, "Radiation properties of spherical and cylindrical rectangular microstrip patch antennas," Automatika Journal, Vol. 43, No. 1-2, 69-74, 2002.

[18] Jain-Ming, J., J. A. Berrie, R. Kipp, and S. Lee, "Calculation of radiation patterns of microstrip antennas on cylindrical bodies of arbitrary cross section," IEEE Transaction, Antennas and Wave Propagation, Vol. 45, No. $1,126-132$,

[19] Ho, C. H., P. K. Shmaker, K. Smith, and J. W. Liao, "Printed cylindrical slot antenna for commercial applications," Electronic Letters, Vol. 32, No. 3, 151$153,1996$.

[20] Pirai, M. and H. R. Hassani, "L-probe fed circular polarized wideband planar patch antenna on cylindrical structure," Progress In Electromagnetics Research C, Vol. 3, 161-167, 2008

[21] Huang, J., R. Vahldieck, and H. Jin, "Microstrip discontinuities on cylindrical surfaces," IEEE MTT-S Symposium, Vol. 3, 1299-1302, Jun. 1993.

[22] $\mathrm{Su}, \mathrm{H}$. and K. Wong, "Dispersion characteristics of cylindrical coplanar waveguides," IEEE Trans. Microwave Theory and Techniques, Vol. 44, No. 11, 2120-2122, 1996.

[23] Ning, Y., S. Y. Tat, N. Xiao-Chun, and L. Le-Wei, "Analysis of probe-fed conformal microstrip antennas on finite grounded substrate," IEE Trans. Ant. and Propag., Vol. 54, No. 2, 554-562, 2006.

[24] Geng, J. P., J. J. Li, R. H. Jin, S. Ye, X. L. Liang, and M. $\mathrm{Z}$. Li, "The development of curved microstrip antenna with defected ground structure," Progress In Electromagnetics Research, Vol. 98, 53-73, 2009.

[25] Josefsson, L. and P. Persson, Conformal Array Antenna Theory and Design, IEEE Press, 2006.

[26] G. Jegan. A.Vimala Juliet. G. Ashok Kumar, "Multi Band Microstrip Patch Antenna for Satellite Communication" 2010 IEEE.

[27] Balanis, C. A., Antenna Theory, Analysis and Design, John Wiley and Sons, Inc., 1997.

[28] Brajlata Chauhan, Sandip Vijay and S.C Gupta "Comparative analysis of Microstrip Patch Antenna using different substrates and observe effect of changing parameter at $5.4 \mathrm{GHz}$ " Conference on Advances in Communication and Control Systems 2013 (CAC2S 2013).

\section{AUTHOR PROFILE}

Prashansha kumari was born in 1991. She received her B.E degree in Electronics and Communication Visvesvaraya Technology University Bangalore in 2013, India and also pursuing her M.Tech from DITU Dehradun Uttrakhand. Her research interest includes design and characterization of implantable microstrip patch antenna and conformal antenna.

Mrs. Brajlata Chauhan received her Master degree in Digital communication from Uttrakhand technical University Dehradun Uttrakhand in 2010, India and also pursuing her $\mathrm{PhD}$ from UTU Dehradun UK. She is working in Dehradun Institute of Technology, Dehradun as AP. A life member of Institute of Electronics and Telecommunication Engineers India. She is having teaching experience of 11 years in Engineering Institutions. 
Sandip Vijay received B.Sc. (Engg.) from PIT Patna (Erstwhile Magadha University) in 1998 M.Tech. (Electronics\& Comm. Engg.) In 2000, the member of IEEE (USA), NSBE(USA), IANEG (USA), ISOC (USA),Life Member of ISTE(INDIA) has published over Eighty research papers in national and international journals/conferences and IEEE Proceeding publication in field of Wireless \& Digital Communication Network, and supervised more than 40 projects/dissertation of M.Tech. \& B.Tech. Students. He started his career as R \& D Engineer in Dell Computers in the field of Quality Assurance Engineer then joined teaching profession as a Lecturer and later on promoted as Asst.Professor (EC) in GEIT, Uttranchal Technical
University, (Now Graphic Era University). He has successfully completed major research projects independently by VSI \& DA-IICT, Gandhi Nagar, in the field of VLSI Design. He finished his Doctorate in 2011 from I.I.T. Roorkee in the field of Wireless Computing under Ministry of HRD, Government of India fellowship. Currently working as Associate Professor in Department of ECE \& AEI at Dehradun Institute of Technology (DIT), an autonomous college of Uttrakhand Technical University, Dehradun (Uttrakhand). Total Publication till Date: 82 